\title{
CHAVES PARA CLASSIFICAC̣ÃO DE GALHAS DE CECIDOMYIIDAE (DIPTERA) EM MYRTACEAE NA RESTINGA DA BARRA DE MARICÁ, RIO DE JANEIRO
}

\author{
Valéria Cid Maia ${ }^{1}$
}

\begin{abstract}
KEYS tO SEPARATION OF CECIDOMYIIDAE (DIPTERA) GALLS ON Myrtaceae at Restinga da Barra de Marica, Rio de Janeiro. Keys to Cecidomyiidae galls occuring on Myrtaceae by genus of the host plant, in alphabetical order, are presented. Data on gall makers, predators and inquilinous species are given, as well as illustrations of the galls.

KEY WORDS. Diptera, Cecidomyiidae, Myrtaceae, galls
\end{abstract}

Os Cecidomyiidae (Diptera) na Restinga da Barra de Maricá (Rio de Janeiro), são responsáveis pela indução de várias galhas em Myrtaceae, família de plantas bem representada neste ambiente (SILVA \& SONNER 1984).

Através de observações e estudo do material coletado em excursões periódicas realizadas na Restinga (1986-1994), chaves para a separação das galhas de Myrtaceae foram elaboradas. Elas estão organizadas a partir do gênero da planta hospedeira, em ordem alfabética e incluem as espécies de Cecidomyiidae a elas associadas (galhadores, predadores e inquilinos). As galhas e os Cecidomyiidae estão depositados na coleção de Diptera do Museu Nacional, Universidade Federal do Rio de Janeiro.

Chaves como estas são comumente encontradas na literatura pertinente ao grupo, merecendo destaque as organizadas por HOUARD (1933) e GAGNÉ (1994) para a América do Sul e Região Neotropical, respectivamente, sendo mesmo mais comuns que chaves para identificação de espécies.

Cabe ainda acrescentar que a morfologia da galha é considerada de grande valor taxonômico (devido à alta especificidade em relação à espécie galhadora e planta hospedeira). Além disso, seus caracteres são de mais fácil observação do que os das fases imaturas ou adultos do cecidomíideo, dado o tamanho diminuto destes.

Os caracteres utilizados referem-se principalmente à forma da galha, coloração e órgão de ocorrência na planta hospedeira.

1) Departamento de Entomologia. Museu Nacional. Quinta da Boa Vista. São Cristóvão. 20940-(040) Rio de Janeiro, Rio de Janeiro, Brasil. 
Chaves para separação das galhas de Cecidomyiidae em Myrtaceae, na Restinga de Barra de Maricá (Rio de Janeiro)

*. Distribuição geográfica das plantas hospedeiras: BRASIL.

\section{Eugenia}

1a - Galhas formadas por um intumescimento e enrolamento da borda foliar (Fig. 1) Planta hospedeira: E. rotundifolia Casar.

Predador: Lestodiplosis sp.

$1 \mathrm{~b}$ - Galhas não formadas por intumescimento e enrolamento da borda foliar . .2

2a - Galhas formadas por intumescimento do limbo foliar . . . . . . . . . . 3

$2 b-$ Galhas não formadas por intumescimento do limbo foliar . . . . . . . . . 4

3a - Galhas amarelas, nitidamente convexas (Figs 2a,b) .

Resseliella sp. e Dasineura globosa Maia. Planta hospedeira: E. rotundifolia.

$3 \mathrm{~b}$ - Galhas verdes ou vermelhas e ligeiramente convexas (Figs 3a,b) . . . . . . Neolasioptera eugeniae Maia Planta hospedeira: E. uniflora Linnaeus.

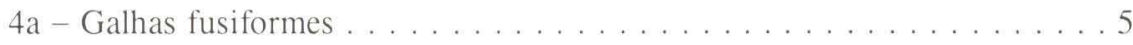

$4 b-$ Galhas com outras formas . . . . . . . . . . . . . 6

5a - Galhas vermelhas, em geral na superfície abaxial das folhas (Figs 4a,b) . . . Stephomvia tetralobae Maia Planta hospedeira: E. copacabanensis Kiaersk.

Inquilino: Trotteria sp.

$5 b$ - Galhas em ambas as superfíceis foliares (Figs 5a,b,c) . . . . Cecidomyiidi Planta hospedeira: E. uniflora.

$6 a$ - Galhas cilíndricas, castanhas externamente (quando maduras) e brancas internamente, ocorrendo nas nervuras foliares e em caules (Figs 6a,b). . . Stephomyia rotundifoliorum Maia Planta hospedeira: E. rotundifolia.

$6 \mathrm{~b}$ - Galhas espiraladas, vermelhas, no limbo foliar (Figs 7a,b) . . . . . . . Stephomyia espiralis Maia Planta hospedeira: E. copacabanensis.

\section{Myrcia}

- Galhas amareladas, alongadas, com sulcos longitudinais, ocorrendo no caule ou a partir de gemas apicais e axilares (Fig. 8) . . . . . . . . . . . . Planta hospedeira: $M$. ovata Camb. 


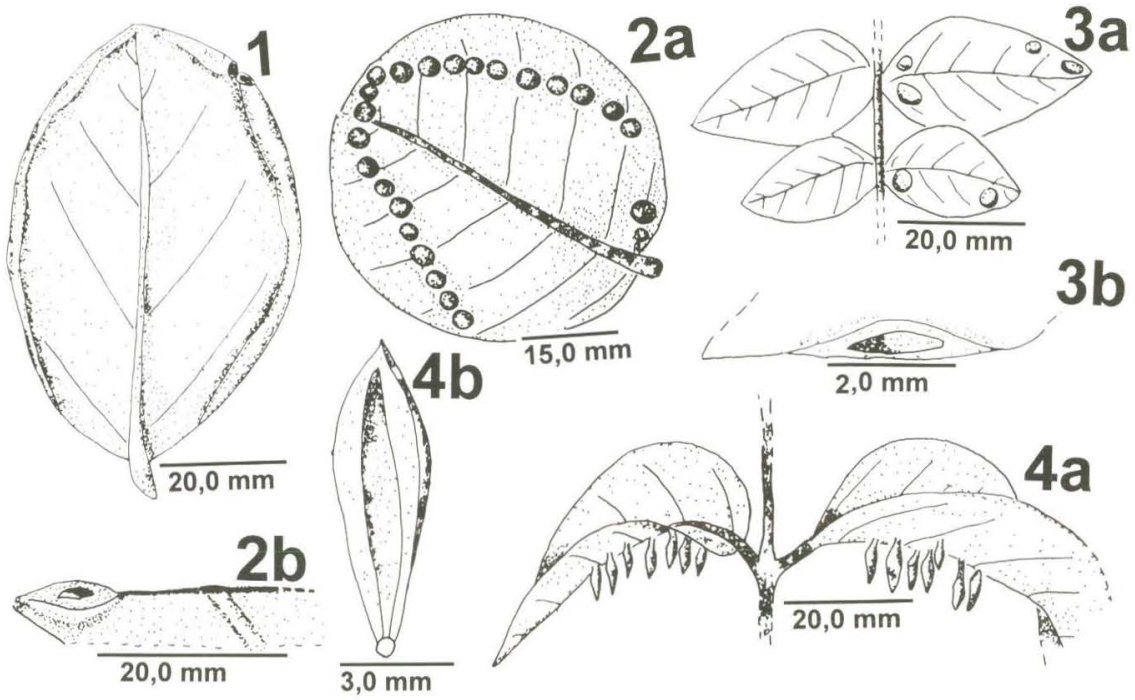

Figs 1-4. Galhas de Cecidomyiidae em Myrtaceae. (1-2) Em Eugenia rotundifolia; (1) enrolamento da borda foliar, aspecto geral; (2) galha convexa. (3) Em E. uniflora, parenquimática. (4) Em Eugenia copacabanensis, fusiforme. (a) Aspecto geral, (b) secção transversal.

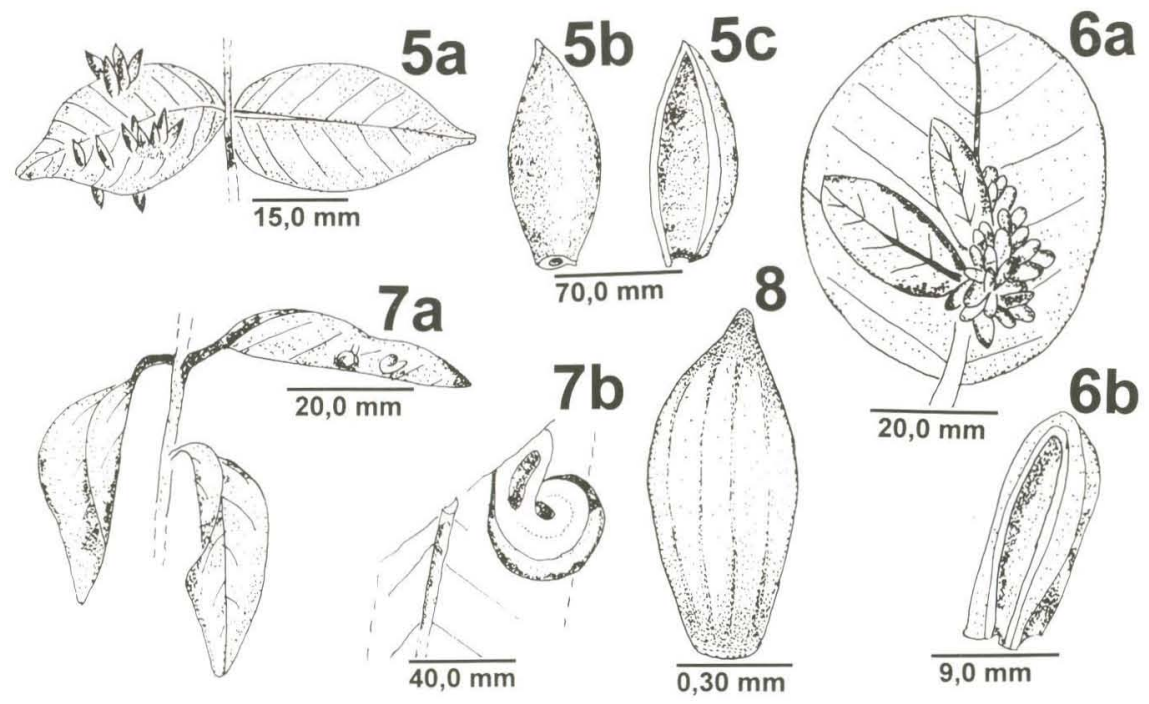

Figs 5-8. (5) Em E. uniflora, fusiforme (a) aspecto geral, (b) ampliado, (c) secção transversal; (6) em E. rotundifolia, cilíndrica, (a) aspecto geral, (b) secção transversal; (7) em E. copacabanensis, espiralada, (a) aspecto geral, (b) secção transversal; (8) em Myrcia ovata, aspecto geral. 


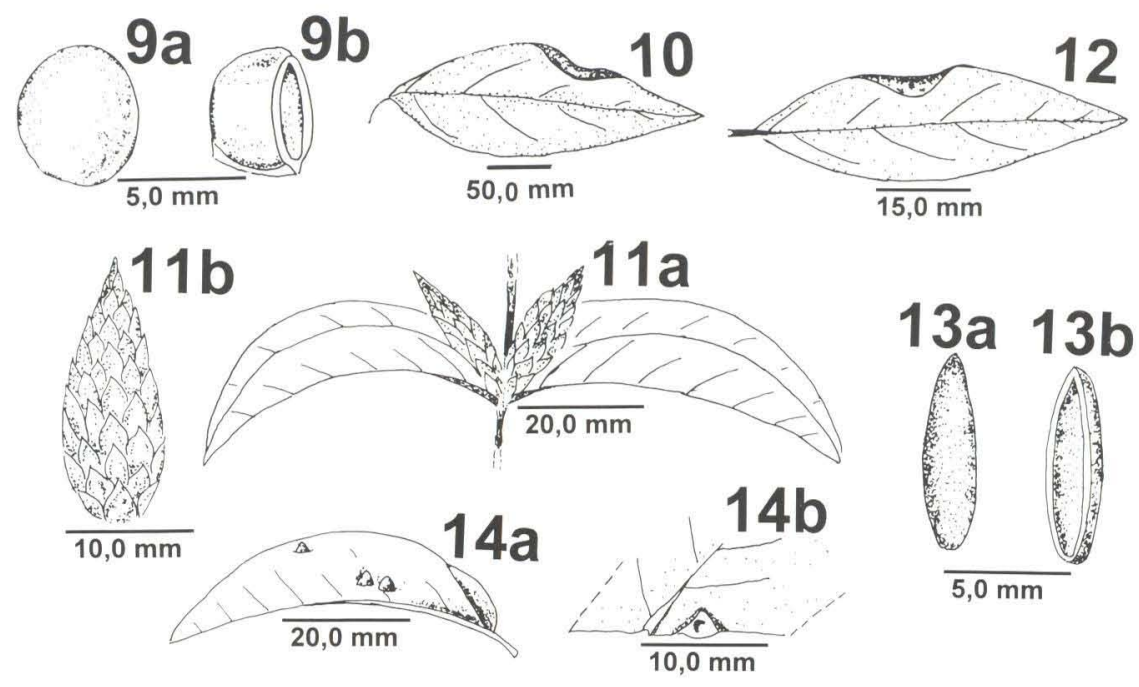

Figs 9-14. (9-10) em Myrciaria floribunda; (9) bivalva, (a) aspecto geral, (b) secção transversal; (10) enrolamento da borda foliar, aspecto geral. (11-14) Em Neomitranthes obscura; (11) galhas de gemas apicais ou axilares, (a) aspecto geral, (b) ampliado, (12) enrolamento da borda foliar, aspecto geral; (13) elíptica, (a) aspecto geral, (b) secção transversal; (14) triangular, (a) aspecto geral, (b) secção transversal.

\section{Myrciaria}

1a - Galhas de gemas apicais ou axilares, pecioladas, amarelas, formadas por duas valvas (Figs 9a,b) . . . . . . . . Myrciariamyia bivalva Maia Planta hospedeira: $M$. floribunda (Camb.) Legr.

1b - Galhas foliares, formadas por intumescimento e enrolamento da borda (Fig. 10) . . . . . . . . . . . Dasineura myrciariae Maia e Lestodiplosis sp. Planta hospedeira: $M$. floribunda.

\section{Neomitranthes}

1a - Galhas de gemas apicais e axilares, verdes, de formato semelhante a uma pinha (Figs 11a,b) . . . . . . . . . . . Neomitranthella robusta Maia Planta hospedeira: N. obscura (DC.).

$1 \mathrm{~b}-$ Galhas foliares . . . . . . . . . . . . . . . . . . . . .

2a - Galhas formadas por intumescimento e enrolamento da borda da folha (Fig. 12) . . . . . . . . . . . . Clinodiplosini e Dasineura tavaresi Maia Planta hospedeira: $N$. obscura.

$2 b$ - Galhas não formadas por intumescimento e enrolamento da borda foliar. . 3

Revta bras. Zool. 12 (4): 1009 - 1013, 1995 
3a - Galhas alongadas, elípticas, vermelhas ou verdes (Figs 13a,b) . . . . . . Stephomyia mina Maia Planta hospedeira: N. obscura.

$3 b-$ Galhas curtas, triangulares, vermelhas (Figs 14a,b). . . . . Cecidomyiinae Planta hospedeira: N. obscura.

AgRadecimentos. A Dra. Márcia Souto Couri (Museu Nacional) pela leitura crítica deste artigo: aos botânicos do Museu Nacional e do Jardim Botânico do Rio de Janeiro pela identificação das plantas hospedeiras; ao Sr. Atídio Manhães (Instituto de Biologia. Universidade Federal do Rio de Janeiro) pelos desenhos das galhas (exceto a de Mrrcia ovata); ao Sr. Luiz Antônio Alves Costa (Museu Nacional) pelo desenho da galha de M. ovata e ao Dr. Ricardo Monteiro (Instituto de Biologia, Universidade Federal do Rio de Janeiro) pela doação do material referente a Myrciamvia maricaensis.

\section{REFERÊNCIAS BIBLIOGRÁFICAS}

Gagné, R.J. 1994. The Gall Midges of the Neotropical Region. Ithaca, Cornell University Press, 352p.

Houard, C. 1933. Les Zoocécidies de Plantes de l'Amérique du Sud et de l'Amérique Central. Paris, Hermann et Cia, 519p.

Silva, J.G. DA \& G.V. SOMmer. 1984. A Vegetação de Restinga na Barra de Maricá, RJ, p.217-224. In: L.D. DE LACERDA; R. CERqueIRA \& B. TURCQ (Eds). Restingas: Origem, Estrutura, Processos. Niterói, CEUFF, 475p. 